\title{
Fulminant AURICULAR MUCORMyCosis IN A DIABETIC PATIENT
}

Clin Biomed Res. 2017;37(4):362-365

1 Head and Neck Surgery Department, Ana Nery Hospital. Santa Cruz do Sul, RS, Brazil.

2 Laboratório Hermes Pardini. Belo Horizonte, MG, Brazil.

3 Department of Clinical Medicine, Ana Nery Hospital. Santa Cruz do Sul, RS, Brazil.

Corresponding author: Fábio Muradás Girardi fabiomgirardi@gmail.com Head and Neck Department, Ana Nery Hospital

Rua Pereira da Cunha, 209.

6835-090, Santa Cruz do Sul, RS, Brazil.
Fábio Muradás Girardi ${ }^{1}$, Anderson Lima da Rocha², Mireille Angelo Bernardes Sousa ${ }^{2}$, Michelle Virginia Eidt ${ }^{3}$

\section{ABSTRACT}

Human mucormycosis is an atypical fungal infection that commonly affects the skin, but rarely the auricular region. A 32-year-old diabetic woman, agricultural worker, was admitted with swelling, redness and mild signs of epidermolysis of the left ear, associated with intense pain, facial paralysis and septic signs. The ear cellulitis evolved into necrosis of the same region on the following day. Surgical debridement was performed and antimycotic therapy was started with poor response. The patient died in 48h. Culture was confirmatory for Rhizopus sp.

Keywords: Mucormycosis; fungal infections; diabetes; Rhizopus

Mucormycosis is a rare but aggressive fungal infection, which occurs most often among patients with diabetes mellitus and other immunosuppressed individuals ${ }^{1}$. Most cases are associated to Rhizopus sp, a genus of common saprophytic fungi on plants and decaying organic matter. Most human infections are rhinocerebral and sinopulmonary. Cutaneous mucormycosis are also frequent and generally result from direct inoculation of fungal spores in the skin through any kind of injury, causing tissue necrosis by angioinvasion. The authors reported a case of a 32-year-old diabetic woman, agricultural worker, admitted to this service with a fulminant auricular mucormycosis.

\section{CASE REPORT}

A 32-year-old female patient from the public health system, with type 1 diabetes not adequately managed, was admitted to the author's service with pain on the left ear and tachypnea for 2 to 3 days. She reported a story of periauricular wounds about two days after the onset of the symptoms. She was an agricultural worker in the tobacco industry, and had been engaged in cleaning tobacco leaf stitching machines in the previous days. On clinical examination, a peripheral ipsilateral facial palsy was present. There was swelling, redness and mild signs of epidermolysis of the left ear, associated with intense pain, respiratory frequency of $25 \mathrm{bpm}$ and heart rate of $105 \mathrm{bpm}$. There was no fever. A significant ear canal edema made it impossible to perform a satisfactory otoscopy. The serum glucose level on arrival was $350 \mathrm{mg} / \mathrm{dL}$. The first clinical hypothesis was a malignant external otitis caused by Herpes Zoster or bacterial infection. A 24-hour scheme of intravenous acyclovir and antibiotics was introduced. Clinical management for decompensated diabetes was also performed. In 24 hours, the patient got worse. Fever was present. The left auricular region started to show necrotic signs and she required intensive care for respiratory and hemodynamic support. The cranial CT showed no signs of fasciitis, mastoiditis or damage to the central nervous system. In few hours, the necrotic area of the ear became larger (Figure 1) and an urgent extensive debridement was performed, including ear amputation and resection of peripheral soft tissues. During the surgical procedure, there were signs of arterial and venous thrombosis and extensive gangrene of tissues, without purulent secretion. Mucormycosis was suspected and liposomal amphotericin B was introduced. It was observed a mild clinical improvement after 6 hours of antifungal administration. However, on the following day, there were signs of mold growing on the surgical bed and an enlargement of the necrotic area (Figure 2). The gangrene area involved nearly half of the 


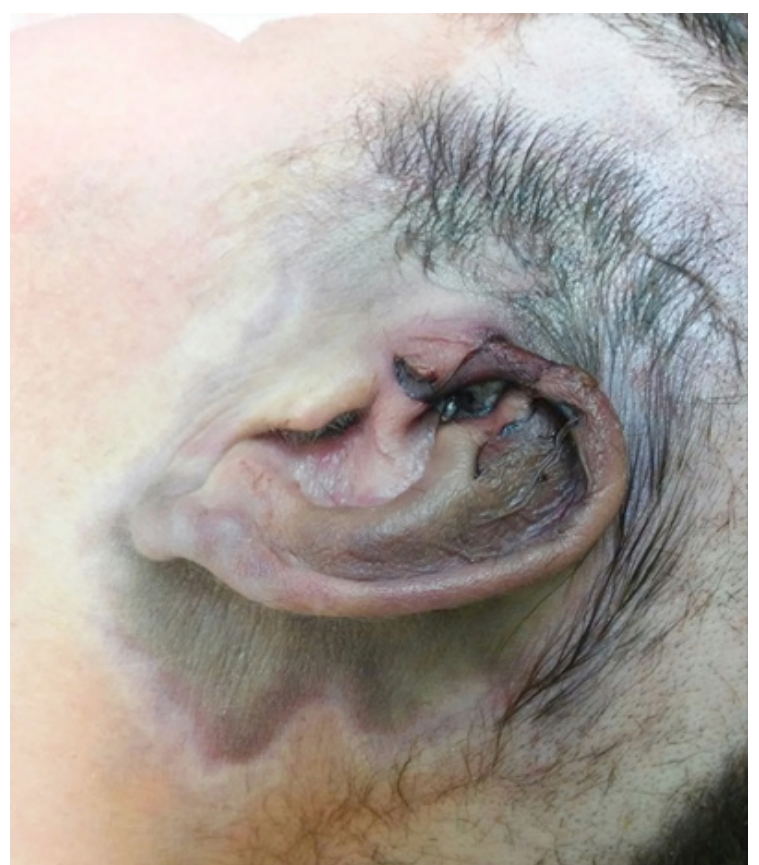

Figure 1: Preoperative appearance (about 24h after initial presentation). Note the large necrotic area around the left ear.

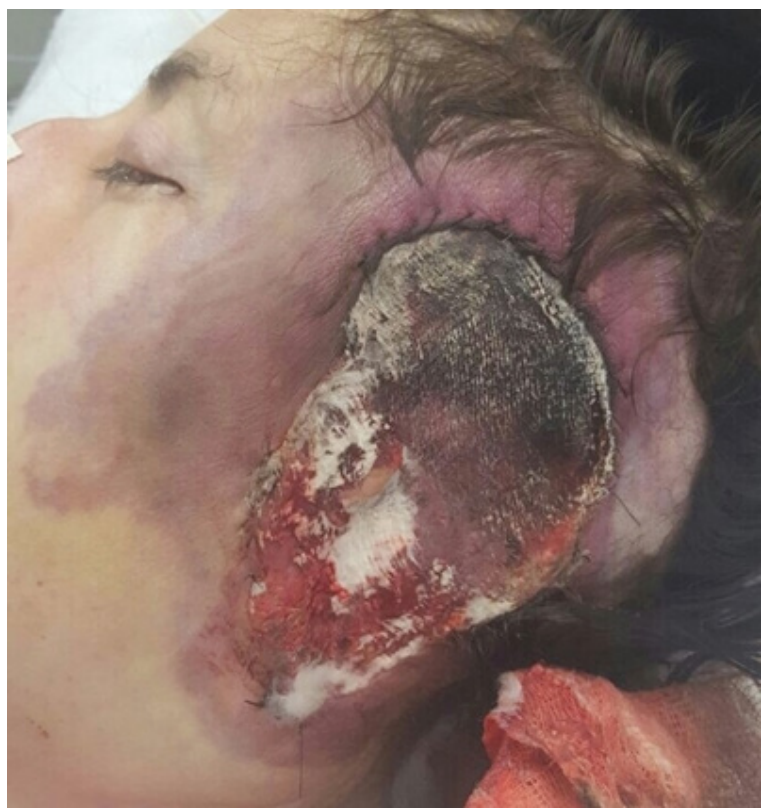

Figure 2: A day after surgical debridement. Note the signs of mold growing on the surgical bed and the enlargement of the necrotic area.

patient's face, including oral cavity and the left eye globe. Clinical parameters got worse. The patient's family did not authorize a new debridement and brain death diagnosis was established after 48 hours. Culture was confirmatory for Rhizopus sp (Figure 3).

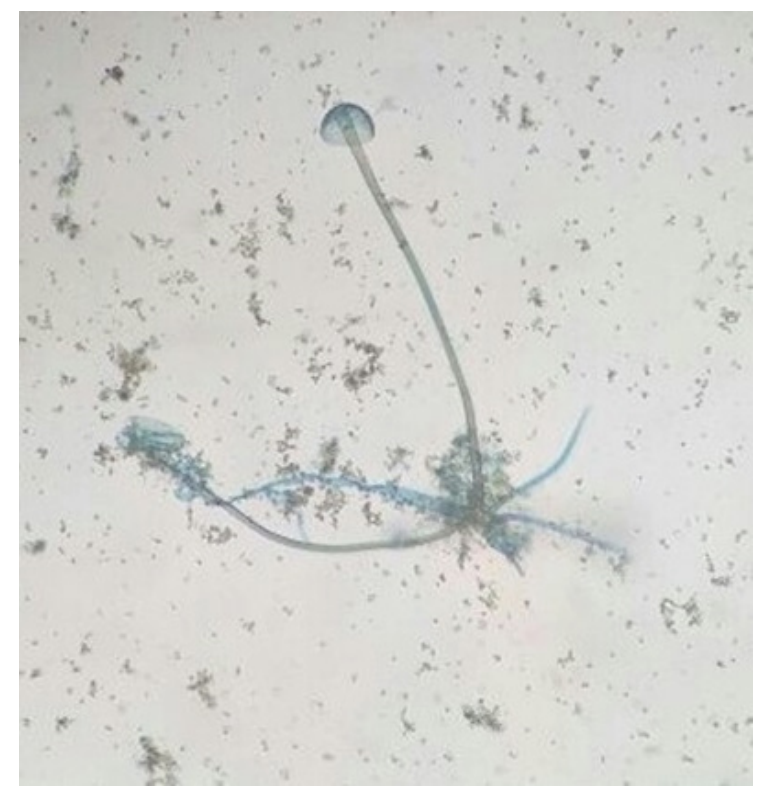

Figure 3: Rhizopus sp micromorphology. View from slide culture $(40 \mathrm{x})$. Note the presence and orientation of rhizoids.

\section{DISCUSSION}

Mucormycosis is known as a rare disease, more prevalent among adults and men. However, it is becoming more frequent, being the third most common invasive mycosis in order of importance, after Candidiasis and Aspergillosis, in patients with hematological and allogeneic stem cell transplantation ${ }^{1,2}$. It is mostly seen among patients with diabetes mellitus (36-88\%), individuals immunosuppressed by chemotherapy or allogeneic stem cell transplants, and patients suffering from different kinds of physical traumas ${ }^{1}$. Although with some differences in fungal classes involved in human infections, the terms mucormycosis, zygomycosis and phycomycosis are commonly used interchangeably ${ }^{1}$.

Mucorales fungi cause most cases of human mucormycosis, and the species of genus Rhizopus is found in over $80 \%$ of mucormycoses ${ }^{2}$. Rhizopus is a genus of common saprophytic fungi on plants and some parasites. They are often isolated from soil, decaying organic material and fruits, but can also be found on vegetables, jellies, syrups, leather, bread, peanuts, and tobacco ${ }^{3}$. They are thermotolerant, although they usually prefer a humid and warm environment ${ }^{1}$.

Most human infections are rhinocerebral and sinopulmonary, generally a result of fungal inhalation. Cutaneous mucormycosis results from 
direct inoculation of fungal spores in the skin. These fungal species are vasotropic, causing tissue necrosis by angioinvasion and subsequent thrombosis. They begin usually at the site of penetration, following some injury. Although in this reported case the patient could not recall a history of trauma, other cutaneous mucormycosis were also reported secondary to minor injuries. In this particular case, the history of activity in tobacco culture draws attention, especially the fact of having cleaned tobacco leaf stitching machines recently.

According to the extent of the infection, cutaneous mucormycosis are classified as localized (affecting only the skin or subcutaneous tissue); deep (affecting muscles, tendons, or bone); and disseminated (affecting other noncontiguous organs). Its onset may be gradual and slow, or fulminant, leading to gangrene and hematogenous dissemination. The typical presentation of cutaneous mucormycosis is a necrotic eschar accompanied by surrounding erythema and induration. However, a disease spectrum ranging from a localized cutaneous wound to a disseminated and fatal infection may be seen, especially in immunocompromised hosts. In patients with opened wounds, lesions may have a cotton-like appearance, resembling that of bread mold (See Figure 3) 4,5 . Differential diagnosis must be made with pyoderma gangrenosum, bacterial synergistic gangrene, or other infections produced by bacteria or other fungi ${ }^{1}$.

Cutaneous infections frequently occur in the limbs, usually as a dolorous erythematous to violet lesion, becoming necrotic, with discharge of a malodorous putrid and black exudate ${ }^{2}$. The observed auricular localization is exceptional ${ }^{6}$, and only other five confirmed cases $^{6-10}$ were found in the literature. Tuzcu et al. described a fulminant case in a 17-year-old girl with diabetic ketoacidosis, septic signs and cellulitis of right external ear. A black necrotic scar on the same ear appeared also only on the day after the initial presentation.

The clinical diagnosis of mucormycosis is challenging. Patients are often treated presumptively as histological and microbiological proof is time-consuming ${ }^{1}$. Ideally, a deep and early biopsy, with direct microscopy, culture and histopathology, would optimize the outcomes. A superficial scraping may only show necrotic tissue. Identification is based on microscopy. Mucorales hyphae are short, about $5 \mu \mathrm{m}$ in width and 20-50 $\mu \mathrm{m}$ long, and non-septate. Another microscopic consideration is that hyphae generally have ramifications at $90^{\circ}$ angles. This feature is useful in histological examination and direct microscopy for differential diagnosis with Aspergillus spp and Fusarium spp.

In culture, they usually grow rapidly ( $3-5$ days) at $25-28{ }^{\circ} \mathrm{C}$. Mucorales form hairy, wooly, gray-white colonies that fill the tubes and Petri plates. Identification is done based on micromorphological and biochemical criteria. In histology, inflammatory granulation tissue with edema, necrosis, polymorphonuclear cells and plasma cells, as well as thromboses and vessel infarction are seen. The hyphae have a propensity for invasion of the walls of veins and arteries. Thick, hyaline, coenocytic, branched hyphae can be visualized by the PAS, Gomori and Grocott stain².

Recently some articles were published regarding the application of mass spectrometry procedure based on the detection of a serum disaccharide (MS-DS) in fungal infections. Regarding specifically mucormycosis, the new technique preceded the date of a definite diagnosis. Until this moment, none of the serological tests currently on the market were efficient for the diagnosis. Apparently MS-DS could fill this gap, improving the promptness of a clinical diagnosis of this high lethal condition ${ }^{11}$.

In most cases, the infection is rapidly progressive with high risk of death, especially if underlying risk factors (i.e., metabolic acidosis) are not corrected in time $^{1}$. The mortality rate varies according to the site of infection, host and time of diagnosis. Treatment success depends on the condition of the patient, associated factors, and the promptness of the diagnosis. For cases with cutaneous involvement, aggressive debridement with removal of all necrotic areas, in combination with liposomal amphotericin $B$ are the most effective treatments ${ }^{2}$. Although the antifungal susceptibility testing is only marginally recommended for guidance of the treatment of patients with this disease, it may differ between species. Amphotericin B is still considered the most active drug against most species of Mucorales. Nevertheless, posaconazole and more recently isavuconazole are currently strongly recommended as salvage treatments for patients with mucormycosis refractory to Amphotericin or those intolerant to this agent. Although data are fragmentary and restricted to the most common Mucorales species, combination of antifungal drugs may represent a promising therapeutic strategy, as treatment efficacy may be improved by the synergistic interaction of drugs with distinct targets of action ${ }^{12}$. 


\section{REFERENCES}

1. Petrikkos G, Skiada A, Lortholary O, Roilides E, Walsh TJ, Kontoyiannis DP. Epidemiology and clinical manifestations of mucormycosis. Clin Infect Dis. 2012;54(Suppl 1):S2334. PMid:22247442. http://dx.doi. org/10.1093/cid/cir866.

2. Perusquía-Ortiz AM, VázquezGonzález D, Bonifaz A. Opportunistic filamentous mycoses: aspergillosis, mucormycosis, phaeohyphomycosis and hyalohyphomycosis. J Dtsch Dermatol Ges. 2012;10(9):61121, quiz 621-2. PMid:22925358. http://dx.doi.org/10.1111/j.16100387.2012.07994.x.

3. Kirk PM, Cannon PF, Minter DW, Stalpers JA. Dictionary of the Fungi. 10th ed. Wallingford: CABI; 2008. 599 p.

4. Chawla R, Sehgal S, Kumar SR, Mishra B. A rare case of mucormycosis of median sternotomy wound caused by Rhizopus arrhizus. Indian J Med Microbiol. 2007;25(4):419-21. PMid:18087101. http://dx.doi.org/10.4103/02550857.37355.
5. Kordy FN, Al-Mohsen IZ, Hashem F, Almodovar E, Al Hajjar S, Walsh TJ. Successful treatment of a child with posttraumatic necrotizing fasciitis caused by Apophysomyces elegans: case report and review of literature. Pediatr Infect Dis J. 2004;23(9):877-9. PMid:15361732. http://dx.doi.org/10.1097/01. inf.0000136870.17071.fd.

6. Bellazreg F, Hattab Z, Meksi S, Mansouri S, Hachfi W, Kaabia N, et al. Outcome of mucormycosis after treatment: report of five cases. New Microbes New Infect. 2014;6:4952. PMid:26137308. http://dx.doi. org/10.1016/j.nmni.2014.12.002.

7. Oktay MF, Askar I, Kilinç N, Tuzcu A, Topçu I. Auricular mucormycosis: a case report. Kulak Burun Bogaz Ihtis Derg. 2007;17(4):228-30. PMid:18187976.

8. Tuzcu A, Bahceci M, Celen MK, Kilinc N, Ozmen S. Necrotizing (malignant) otitis externa: an unusual localization of mucormycosis. Indian

\begin{abstract}
J Med Microbiol. 2006;24(4):28991. PMid:17185850. http://dx.doi. org/10.4103/0255-0857.29390.
\end{abstract}

9. Wall SJ, Lee KH, Alvarez JD, Bigelow DC. Quiz case 1. Cutaneous mucormycosis of the external ear. Arch Otolaryngol Head Neck Surg. 2000;126(2):236, 238-9. PMid:10680881. http://dx.doi. org/10.1001/archotol.126.2.236.

10. Yun MW, Lui CC, Chen WJ. Facial paralysis secondary to tympanic mucormycosis: case report. Am J Otol. 1994;15(3):413-4. PMid:8579151.

11. Mery A, Sendid B, François N, Cornu M, Poissy J, Guerardel Y, et al. Application of mass spectrometry technology to early diagnosis of invasive fungal infections. J Clin Microbiol. 2016;54(11):2786-97. PMid:27605710. http://dx.doi. org/10.1128/JCM.01655-16.

12. Dannaoui E. Antifungal resistance in mucorales. Int J Antimicrob Agents. 2017;S0924-8579(17):30302-3.

Received: June 28, 2017 Accepted: Sept 28, 2017 